\title{
THE IMPACT OF ENTROPY ON THE EFFICIENCY OF EXPRESS COURIER SYSTEMS
}

\author{
Dr Momčilo Dobrodolac* \\ University of Belgrade, Faculty of Transport and Traffic Engineering, Belgrade, Serbia \\ Dragan Lazarević \\ University of Belgrade, Faculty of Transport and Traffic Engineering , Belgrade, Serbia \\ Dr Libor Švadlenka \\ University of Pardubice, Jan Perner Transport Faculty, Pardubice, Czech Republic \\ Dr Mladenka Blagojević \\ University of Belgrade, Faculty of Transport and Traffic Engineering , Belgrade, Serbia
}

The efficiency of organization depends on the level of entropy. Most often, if the entropy is higher, efficiency is lower, and conversely. The model proposed in this paper involves a measurement of the relative efficiency of courier delivery areas - CDA formed to be served by a courier. A question of forming the CDAs is one of the most important in organizing an express courier system. For measurement purpose we used Data envelopment analysis method - DEA. The obtained results indicated which zones are characterized by the presence of entropy. By further analysis, i.e. by calculation the target values for inefficient CDAs we get the directions about possible points where the changes are needed to achieve an improvement. This was done based on the determination of reference efficient decision making units - DMUs, in this case CDAs. Beside this we ranked all the efficient DMUs. The proposed methodology was tested and verified in the case of express courier system of the Post of Serbia which is called Post Express. The empirical example is based on data collected in observation during 30 working days analyzing six CDAs.

Key words: Entropy, Efficiency, DEA, Express service, Zoning

\section{INTRODUCTION}

If we assume the company does not include the employees but only a technology, its disorder or entropy would be minimal. When we introduce a human factor, the system takes the character of stochasticity. In this way, humans become a factor of increased entropy because of a deviation between the actual and objectively expected productivity. Therefore, the entropy is seen as a measure of disorganization of the system.

Organizing the unnatural entities or artificial systems and bringing the natural elements in unnatural organized structure is the primary activity of people for the purpose of domination and raising the standards and quality of life. In the modern environment, a company is an executor of processes which transform inputs into the required outputs. By their activities the companies reduce disorders in the artificial systems, but also bring an increase of entropy in a natural system due to uncontrolled exploitation of natural resources and general deterioration of the natural environ- ment. In accordance with the law of conservation of energy, by using the natural resources companies reduce the energy in the natural system and increase it in artificial ones [08].

The postal system is an artificial system which is based on a strongly developed logistic infrastructure. Its role involves the exploitation of postal traffic, i.e. the collection, transportation and delivery of postal items [14]. A proper functioning of the postal system largely depends on human factors; therefore, there is a need to locate the sources of entropy in the system.

Each postal company endeavors to meet the needs of customers along with keeping the sustainability in the performance of business processes. A sustainable business involves the fulfilment of economic, environmental and social factors [09]. Accordingly, the goal of each postal company is a well-organized postal network which includes appropriate positioned postal branches on the operating territory, high availability and quality of postal services [11]. 
There are 48 postal operators operating at the postal market in the Republic of Serbia. The most developed network infrastructure and the largest number of services is provided by the Post of Serbia. It is a state owned company which serves as a universal service provider, the only one at the territory of Serbia. According to the Universal Postal Union strategy directions, a liberalization of the postal market is taking place and the impact of competition increases constantly. To keep the leader position at the domestic postal market, it is necessary for the Post of Serbia to monitor, control and improve the efficiency in all segments of the business process. In this way, the impact of entropy in the system should be decreased [08].

Speaking about the efficiency of express courier service, it could be noticed that the main goal of the company would be to serve as much as possible addresses or locations in the stipulated time frame. To achieve this aim adequate resources are used. The manner of their use could be assessed through analysis of some operating parameters such as, in the case of couriers, the distance traveled by the couriers serving their areas, travelling time and the time needed for serving a customer at his/her address.

When we should assess the efficiency of particular units and we are in position to collect data about the input and output parameters, it is very convenient to implement a mathematically grounded technique called DEA - Data Envelopment Analysis. This method is used for various purposes, to assess the efficiency of various companies, departments or lower level elements. The considered units are called DMUs - Decision Making Units in DEA theory. DEA is a mathematical programming technique which determines whether each DMU included in the analysis is efficient or not relative to all other considered units [12].

The efficiency of DMU can be considered as a comparison between observed and optimal values of its output and input. Therefore, it is possible to compare observed output to maximum potential output obtainable by the input, or observed input to minimum potential input required to produce the output, or the combination of these two concepts [13]. In the literature it was first introduced by Charnes, Cooper, and Rhodes (CCR) in 1978 [03].
This paper describes the relationship between the organizational inefficiencies and entropy through indicators obtained by using DEA method in the process of operating performance assessment of the system for express courier service. To illustrate the applicability of the proposed methodology we introduce a case study of courier service of the Post of Serbia which is called Post Express. At the global level, this service is very popular since it a postal service of a high quality offering "door to door" transit of postal items. Considering the case of Serbia, the volumes of this service have been increasing over previous years.

We propose a methodology which considers the relative efficiency of collection/ delivery segments of the territory where Post Express service is offered. There are different territorial segments observed which enabled a conclusion where in the system further analysis and improvements are needed. Inefficiency of the segment is an indicator of the existence of entropy and the need for restructuring.

In this specific case, the observed problem involves determining the relative efficiency of the six territorial segments, i.e. courier delivery areas - CDAs. This implies six linear programming tasks which are solved by the "Excel Solver" program. Besides the calculations of the values of relative efficiency and super efficiency, there is also a sensitivity analysis of the obtained results performed.

By implementing the proposed methodology, a postal company is in the position to locate the problems in organizing its courier service and delivery activities. Therefore, this study could be of a high significance in the field of resource optimization since its implementation leads to the savings in engaged employees, used vehicles, fuels, energy, etc.

\section{THE FUNCTIONING PRINCIPLES AND DESCRIPTION OF THE PROBLEM}

There is a huge competition at the market of express courier services in almost every state. The same is valid in the case of Serbia. Therefore, to survive it is expected from the companies to offer a service of the highest quality and to optimize the use of their resources. To achieve this it is necessary to perform the business activities efficiently in all segments which could be controlled through measuring the efficiency. 
In the system of Post Express, there are several services which differ based on the specified time of collection and delivery of items. One of the main quality indicators of courier service is on time collection and delivery. Namely, according to the company regulations, a courier gets the tasks regarding the collection and delivery to be done in the time period of 80 minutes. Therefore, the problem could be formulated as the matter of forming the appropriate courier zones which should be served in the mentioned time frame.
The zone is a territorial area defined by a group of Postal Address Codes (In Serbian PAK). The recommendation to establish the 80 minutes zones has the aim to make a more equal distribution of tasks between the couriers of one delivery branch. For the six-day working week a courier during his working hours on average serves four 80 minutes zones daily. The assessed times of particular activities performed by a courier are shown in Table 1.

Table 1: The assessed times of particular activities performed by a courier

\begin{tabular}{|c|l|}
\hline $\begin{array}{c}\text { Spent time by a courier } \\
\text { (minutes) }\end{array}$ & \multicolumn{1}{c|}{ Activity performed by a courier } \\
\hline 20 & Preparation for delivery and leaving the postal branch \\
\hline 30 & Pause \\
\hline 20 & $\begin{array}{l}\text { After coming back to the postal branch, calculation of } \\
\text { charged cash, delivered and collected items }\end{array}$ \\
\hline 10 & Travelling from the postal branch to the zone and back \\
\hline 320 & Collection and delivery (four 80 minute zones) \\
\hline 400 & Total working time \\
\hline \hline
\end{tabular}

The design of zones for collection and delivery of express items is performed at the larger territorial levels of entities, such as a city, one or more neighboring municipalities etc. For sizing the zones data from the AVT (Automatic Vehicle Tracking) application are used.

The basic parameters to design the zones are the time needed for serving a customer at his/ her address and traveling time at the zone. On this basis, the application is required to create a report on the position of vehicles with the times of staying at the addresses and travelling times. A report can be displayed in the form of a map with defined coordinates of the visited points. By featuring the information from a real system, different techniques and procedures could be used to improve the business process.

The number of required areas could be defined by the following formula (1):

$$
N Z=\frac{\sum_{i=1}^{n}\left(t s_{i}+t t_{i}\right)}{N W D * 80 \min * 60 \mathrm{sec}}
$$

where $\mathrm{NZ}$ is the required number of zones, $\mathrm{n}$ is the number of visited addresses, tsi is the time needed for serving a customer at his/her address and tti is a traveling time at the zone. NWD denotes the number of working days.
After determination of the number of required zones on the eligible territory, we should create them. Each zone should be formed as a set of delivery areas which are formed for letter-post delivery. In this step we should take into account the time needed for the collection and delivery of express items. As previously mentioned, it is recommended this time to be 80 minutes which is a limitation for incorporating certain delivery area to the considered zone. Created zones are assigned to the couriers. Couriers will serve them, depending on the type of job and defined deadlines. A zone assigned to the courier makes a part of his courier delivery area. Figure 1 shows an example of distribution of zones in the particular territory.

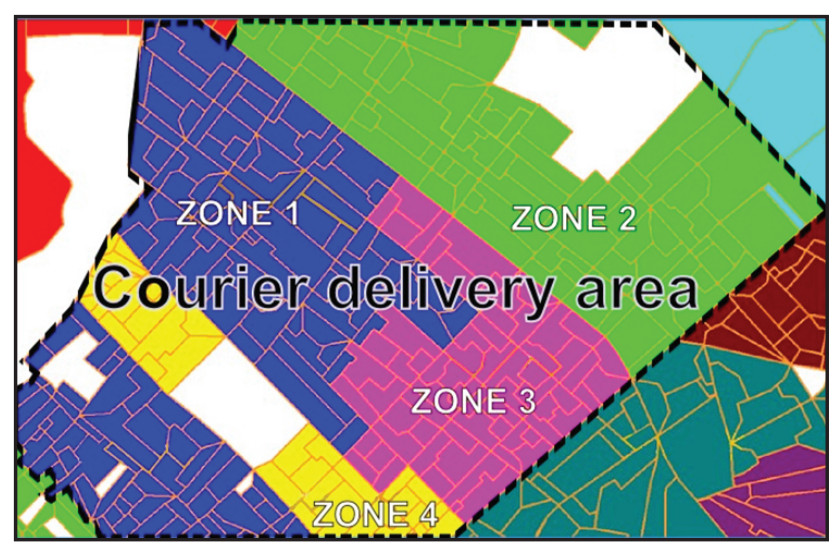

Figure 1: A distribution of zones at CDA 
The generated CDAs should be controlled in sense of efficient functioning. The demand for postal services, including the Post Express service, is characterized by a stochasticity. It is possible that the activities are not carried out efficiently, i.e. because of the entropy (disorganization) a courier is not in a position to perform the service within the stipulated time frame. If this phenomenon appears frequently, it means that there is a need for the restructuring of zones or analysis of couriers work. A useful tool for measuring the relative efficiency of defined CDAs is Data Envelopment Analysis - DEA. Its implementation is described in the next chapter.

\section{THE MEASUREMENT OF RELATIVE EFFICIENCY OF COURIER DELIVERY AREAS}

Essentially there are two main methodologies for measuring technical efficiency: the econometric (or parametric) approach, and the mathematical (or non-parametric) approach. The two techniques use different methods to envelop data, and in doing so they make different accommodation for random noise and for flexibility in the structure of production technology.

Hence they differ in many ways, but the advantages of one approach over the other boil down to two characteristics:

- The econometric approach is stochastic and attempts to distinguish between the effects of noise and the effects of inefficiency, while the linear programming approach is deterministic and under the voice inefficiency melt noise and real inefficiency;

- The econometric approach is parametric and as a result suffers from functional form misspecification, while the programming approach is non-parametric and so it is immune to any form of functional misspecification [10].

In this study we use a non-parametric approach to avoid forming a function which could lead to some sort of misspecification. We implement a CCR DEA model which uses a stricter criteria in forming the efficiency frontier comparing for example to FDH model by Deprins, Simar and Tulkens [05].

The measurement of relative efficiency where there are multiple possibly inputs and outputs was addressed by Farrell [6] and developed by Farrell and Fieldhouse [07], focusing on the construction of a hypothetical efficient unit to act as a comparator for an inefficient unit. Based on their work, the initial Data Envelopment Analysis - DEA model was originally presented by Charnes, Cooper and Rhodes [3]. DEA is a linear programming based technique for measuring the relative performance of organizational units where the presence of multiple inputs and outputs makes comparisons difficult.

An entity whose efficiency should be measured is called Decision Making Unit - DMU. The main characteristic of the DEA method is that it assesses each DMU as a relatively efficient or relatively inefficient. The authors of the method indicate that a DMU can be characterized as efficient only if the following conditions are not fulfilled [04]:

- It is possible to increase any output without increasing any input and without reducing any other output,

- It is possible to decrease any input without reducing any of the outputs and without increasing any other input.

In DEA method multiple inputs are transformed into one virtual input and multiple outputs into one virtual output by weight coefficients. The weight coefficients are defined in the following way: each unit is allowed to determine its own coefficient, with a goal to maximize efficiency, while keeping these coefficients with positive values. Also, the ratio of virtual output and virtual input for each unit cannot be greater than 1 . In this way, efficiency is expressed as the ratio of the weighted sums of its outputs and inputs. Each problem is defined as the task of linear programming which is known as CCR ratio model. The CCR is original model of DEA for evaluating the relative efficiency for a group of DMUs proposed in [3]. The CCR stands for Charnes, Cooper and Rhodes which are the last names of this model creators. Let we suppose that there are $\mathrm{n}$ DMUs with $\mathrm{m}$ inputs and $\mathrm{s}$ outputs. Then $x i j(i=1 \ldots . . m)$ and $y r j(r=1 \ldots . . s)$ are input and output values of DMUj $(j=1 \ldots \ldots . . n)$. The efficiency of such defined DMUj could be determined as follows (2):

$$
\theta_{j}=\frac{\sum_{r=1}^{s} u_{r} y_{r j}}{\sum_{i=1}^{m} v_{i} x_{i j}}, j=1, \ldots, n,
$$

where $(i=1 \ldots . m)$ are input weights given to each of the $m$ inputs and $(r=1 \ldots . . s)$ are output weights given to each of the s outputs. To deter- 
mine the input and output weights the following CCR model is established (3):

$$
\begin{gathered}
\max \quad \theta_{0}=\frac{\sum_{r=1}^{s} u_{r} y_{r 0}}{\sum_{i=1}^{m} v_{i} x_{i 0}} \\
\text { s.t. } \theta_{j}=\frac{\sum_{r=1}^{s} u_{r} y_{r j}}{\sum_{i=1}^{m} v_{i} x_{i j}} \leq 1, \quad j=1 \ldots \ldots n, \\
u_{r} \geq 0, \quad r=1 \ldots \ldots s, \\
v_{i} \geq 0, \quad i=1 \ldots \ldots m .
\end{gathered}
$$

The problem should be converted to the task of linear programming (LP), therefore for the DMU0 it stands (4):

$$
\begin{gathered}
\max \quad \theta_{0}=\sum_{r=1}^{s} u_{r} y_{r 0} . \\
\text { s.t. } \sum_{i=1}^{m} v_{i} x_{i 0}=1 \\
\sum_{r=1}^{s} u_{r} y_{r j}-\sum_{i=1}^{m} v_{i} x_{i j} \leq 0, \quad j=1, \ldots \ldots, n, \\
u_{r} \geq 0, \quad r=1, \ldots \ldots, s, \\
v_{i} \geq 0, \quad i=1, \ldots \ldots, m .
\end{gathered}
$$

If the objective function takes the value 1 , then we say that this DMU0 is efficient, otherwise it is inefficient [04].

The linear model should be solved $n$ times, i.e. for each DMU separately. As a result, the efficient DMUs are determined. There are often more efficient DMUs. One of the shortcomings of the basic DEA model is that all efficient units have the score equal to 1 , and based on this score it is not possible to rank them. To overcome this limitation, Andersen and Petersen [1] developed a modified DEA model. The difference lies in the fact that from the set of conditions, the one related to the efficient DMU is missing, for example DMUe (5):

$$
\max \theta_{e}=\sum_{r=1}^{s} u_{r} y_{r e}
$$

$\sum_{r=1}^{s} u_{r} y_{r j}-\sum_{i=1}^{m} v_{i} x_{i j} \leq 0, \quad j=1, \ldots \ldots, n, j \neq e$

$$
\sum_{i=1}^{m} v_{i} x_{i e}=1
$$

$$
\begin{aligned}
& u_{r} \geq 0, \quad r=1, \ldots \ldots, s, \\
& v_{i} \geq 0, \quad i=1, \ldots \ldots, m .
\end{aligned}
$$

The results of this model are efficiency scores that may be greater than 1 . This allows us to compare the efficient units because there is no limitation about the efficient score.

To determine the sources of inefficiency and the way to improve the performance of inefficient DMUs, the sensitivity analysis can be carried out [02].

Speaking about the case study of CDAs defined to be served by couriers, it is necessary to adjust DEA model to this specific case. A proposed configuration of the research is shown in Figure 2. After we choose a research sample, we should collect data about each courier delivery area. These data should be collected according to the predefined input and output parameters. Then we implement the proposed DEA model. Finally, based on results we take actions to transform inefficient CDA to the efficient one.

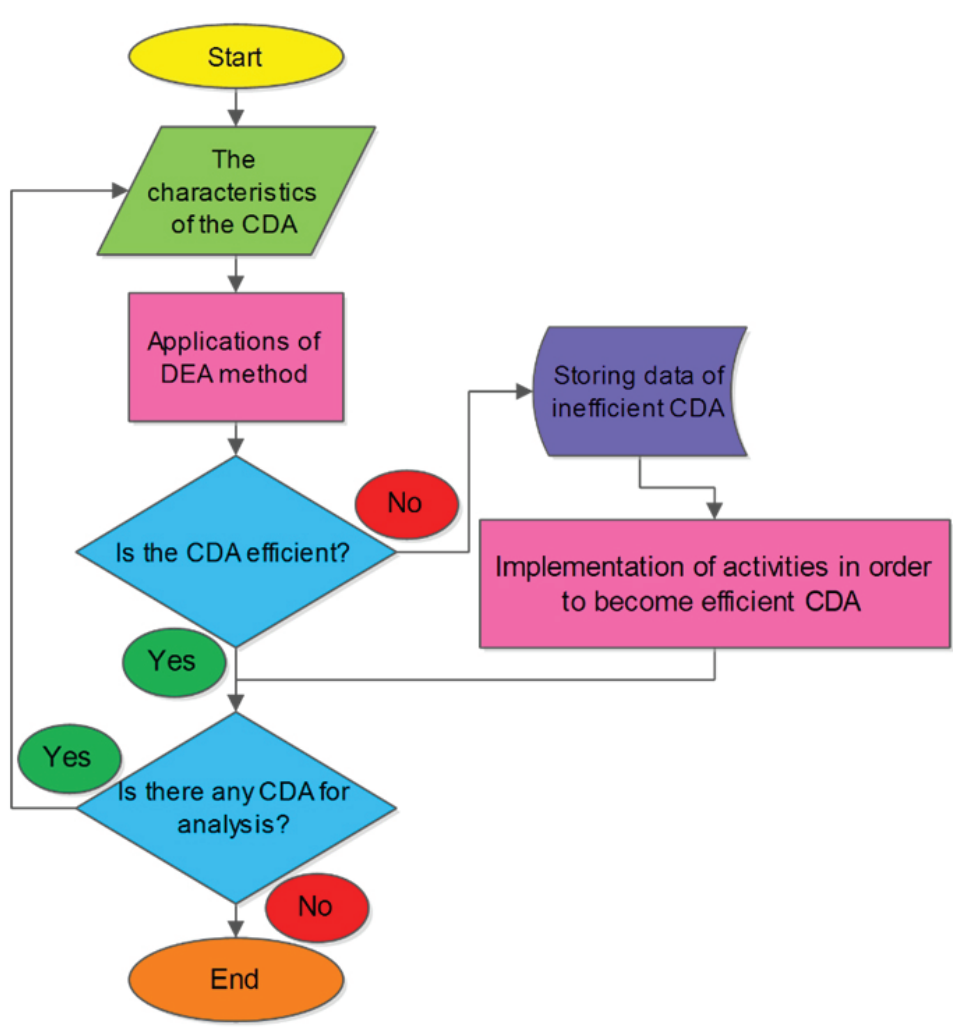

Figure 2: A configuration of the research

\section{EMPIRICAL EXAMPLE}

In the empirical example considered in this study, we analyze six CDAs which are treated as DMUs. The input and output data are shown in Table 2. These data are obtained in observation during 30 working days. 
Table 2: The characteristics of the observed zones

\begin{tabular}{|c|c|c|c|c|}
\hline CDAs (DMU) & $\begin{array}{c}\text { Distance } \\
\text { traveled }[\mathrm{km}] \\
\mathrm{x}_{1}\end{array}$ & $\begin{array}{c}\text { Time spent at served } \\
\text { addresses } \\
{[\mathrm{min}]} \\
\mathrm{x}_{2}\end{array}$ & $\begin{array}{c}\text { Time spent in driving } \\
\text { at CDA [min] } \\
\mathrm{x}_{3}\end{array}$ & $\begin{array}{c}\text { The number of served } \\
\text { addresses } \\
\mathrm{y}_{1}\end{array}$ \\
\hline \hline DMU1 & 810 & 4665 & 1590 & 750 \\
\hline DMU2 & 1007 & 5604 & 1820 & 901 \\
\hline DMU3 & 1410 & 4590 & 2290 & 738 \\
\hline DMU4 & 1025 & 5766 & 1906 & 927 \\
\hline DMU5 & 1440 & 4292 & 2256 & 690 \\
\hline DMU6 & 960 & 5492 & 1860 & 883 \\
\hline
\end{tabular}

A set of input variables include: Distance traveled, Time spent at served addresses and Time spent in driving at CDA, while the number of served addresses represents the output variable.

Distance traveled is a total distance traveled by a courier fulfilling the activities related to the demands of users in his CDA. Time spent at served addresses represents the sum of all times spent at locations where a courier collect or deliver the postal items. Time spent in driving at CDA is a travelling time spent in visiting the locations which should be served. The number of served addresses is the number of locations where a courier provided the services. Minimization of defined inputs, i.e. invested resources, and maximization of outputs leads to the increased efficiency.

Formulation of the linear programming task, when we treat the first territorial segment (DMU 1) as a target decision unit, is (6):The results of

$$
\begin{gathered}
\text { Max } 750 v_{1} \\
810 u_{1}+4665 u_{2}+1590 u_{3}=1 \\
810 u_{1}+4665 u_{2}+1590 u_{3}-750 v_{1} \geq 0 \\
1007 u_{1}+5604 u_{2}+1820 u_{3}-901 v_{1} \geq 0 \\
1410 u_{1}+4590 u_{2}+2290 u_{3}-738 v_{1} \geq 0 \\
1025 u_{1}+5766 u_{2}+1906 u_{3}-927 v_{1} \geq 0 \\
1440 u_{1}+4292 u_{2}+2256 u_{3}-690 v_{1} \geq 0 \\
960 u_{1}+5492 u_{2}+1860 u_{3}-883 v_{1} \geq 0 \\
u_{1} \geq 0.0001 \quad u_{2} \geq 0.0001 \quad u_{3} \geq 0.0001 \quad v_{1} \geq 0.0001 \\
\text { DEA Excel Solver for the given inputs are shown } \\
\text { in Table 3. }
\end{gathered}
$$

Table 3: The efficiency scores of considered DMUs in DEA model

\begin{tabular}{|c|c|}
\hline CDAs (DMU) & Efficiency \\
\hline DMU1 & 1 \\
\hline DMU2 & 1 \\
\hline DMU3 & 0.861557 \\
\hline DMU4 & 1 \\
\hline DMU5 & 0.846896 \\
\hline DMU6 & 1 \\
\hline
\end{tabular}

It can be noticed that the first, second, fourth and sixth CDAs were efficient in terms of the relationship of input and output variables. DMUs with the efficiency score equal to 1 represent the efficiency frontier. The efficiency of the remaining units (DMU 3 and DMU 5) is less than 1 which indicate the existence of entropy in the CDAs, as well as the need to reduce the value of the inputs to become efficient for a given output which represents the customer requirements (it is assumed that all users should be served, i.e. output has a maximum value).

Further, by using the previously described principle of super efficiency we get the final ranking of DMUs, which is shown in Table 4.

Table 4: The final ranking of DMUs

\begin{tabular}{|c|c|}
\hline CDAs (DMU) & Super efficiency \\
\hline \hline DMU2 & 1.004984261 \\
\hline DMU1 & 1.001481754 \\
\hline DMU4 & 1 \\
\hline DMU6 & 1 \\
\hline DMU3 & 0.861557 \\
\hline DMU5 & 0.846896 \\
\hline
\end{tabular}


To determine the sources of inefficiencies and possible ways to improve the performance of inefficient units, it sensitivity analysis [2] should be carried out. The functioning of CDAs which have efficiency less than 1 could be improved through better use or reduction of inputs to obtain the output value. A reference set should be determined for them. A reference set makes at least one efficient DMU with associated dual prices. Table 5 shows the inefficient DMUs and their reference DMUs followed by the appropriate dual price. In both cases the reference set is DMU 2.

Table 5: Parameters for the sensitivity analysis

\begin{tabular}{|c|c|c|}
\hline \hline DMU & Reference DMU & Dual price \\
\hline DMU 3 & DMU 2 & 0.8190899 \\
\hline DMU 5 & DMU 2 & 0.76581576 \\
\hline
\end{tabular}

The reference set composite DMU is used as the focus of what an inefficient DMU would look like if efficient. Vector of the input (output) of DMUs from the reference set is multiplied by the dual price. As a result we get an average vector of the input (output) for a composite DMU, i.e. the target values for inefficient DMU.

Average vectors for DMU3

Average vector of input:

$$
0.8190899 *\left[\begin{array}{l}
1007 \\
5604 \\
1820
\end{array}\right]=\left[\begin{array}{c}
824.8 \\
4590 \\
1490.7
\end{array}\right]
$$

Average vector of output:

$$
0.8190899 *[901]=[738]
$$

Average vectors for DMU5

$$
0.76581576 *\left[\begin{array}{l}
1007 \\
5604 \\
1820
\end{array}\right]=\left[\begin{array}{c}
771.2 \\
4292 \\
1393.8
\end{array}\right]
$$

Average vector of input:

\section{$0.76581576 *[901]=[690]$}

Comparing the average vectors of input and output with the input and output vectors of DMU 3 and DMU 5 from Table 2 the appropriate conclusions could be reached. Composite units in both cases achieve the same output (number of visited addresses) for lower input values.

For DMU 3, i.e. the third zone observed in the empirical example, it is necessary to reduce the distance traveled for $41.5 \%$. This would reduce the traveling time which is anyhow necessary to be reduced by $34.9 \%$ to make this CDA efficient. To become efficient, DMU 5, i.e. the fifth observed CDA, it is necessary to reduce the distance traveled for $46.4 \%$ and traveling time for $38.2 \%$

Based on these indicators, for the observed inefficient CDAs, it is necessary to achieve the proposed targets by using various methodologies and algorithms. If it is not possible to create a more suitable courier route which meets the defined criteria and reduce time spent in driving at CDA, it is necessary to restructure the CDA. Accordingly, a new data collection should be performed using the database of AVT and other applications. This should be used to form new zones and CDAs.

\section{CONCLUSION}

The efforts of humans are directed in placing all the systems and structures in the framework of meeting their needs and improve the quality of life. A disorganization in the system leads to inefficiencies and reduction of business performance. The basic aim is to achieve a maximum efficiency at which the entropy of the system is minimal. Efficiency and entropy can be causal treated, because in most cases higher entropy causes inefficiency, while reduction of entropy increases business efficiency of the organization.

In this study the principle of related entropy and inefficiency is demonstrated in the example of organizing the territorial CDAs for collection and delivery of postal items in Post Express - Department of the Post of Serbia.

We treated six CDAs and applied DEA method for determining the relative efficiency of functioning. Based on the obtained values of efficiency, we found the CDAs characterized by the entropy. Through further analysis it was concluded in which segment of CDA functioning it is necessary to restructure certain activities, to reduce the entropy of the entire business process and establish efficient business operations.

The importance of observing the efficiency of CDAs is in the fact of the cumulative impact of disorganization of certain parts on the entire business system. Namely, it is necessary to decrease entropy in all areas, in order to characterize organization as efficient and successful.

In dynamic and uncertain business environment, companies must continually pursue a policy of reducing the disorganization in order to be efficient. This implies the activities which are based on continuous research and analysis. In this 
specific example, further research could be related to the technology of forming CDAs. Various technologies should be tested according to the methodology described in this paper. In this way, we could reach the information about the most suitable one. Since the Republic of Serbia is a developing country, it is expected that there could be improvement achieved by comparing its technology with the similar companies in the developed countries. After this, an appropriate cost-benefit analysis should be performed to assess how reasonable is to change the working technology.

Beside this recommendation, the analyzed company should take into consideration the complete sample which means that all the demands on the territory of Belgrade should be considered. Since this was an academic study with the aim to demonstrate the applicability of the proposed methodology, our sample consisted of just six CDAs which we analyzed 30 days. To perform the complete reorganization of the whole city, the rest of CDAs should be considered as well.

\section{ACKNOWLEDGEMENT}

The study is a result of Czech project CZ.1.07/2.3.00/30.0058 and Serbian project TR 36022.

\section{REFERENCES}

1) Andersen, P., Petersen, N. C. (1993): A Procedure for Ranking Efficient Units in Data Envelopment Analysis, Management Science, Vol. 39, No. 10, pp. 1261-1264

2) Boile M. (2001): Estimating technical and scale inefficiencies of public transit systems, Journal of Transportation Engineering, Vol. 127, No. 3, pp. 187-193

3) Charnes, A., Cooper, W., Rhodes E. (1978): Measuring the efficiency of decision-making units, European Journal of Operational Research, Vol. 2, No. 6, pp. 429-444

4) Cooper, W., Seiford, L., Tone, K. (2006). Introduction to Data Envelopment Analysis and Its Uses, New York: Springer.

5) Deprins, D., Simar, L., Tulkens, H. (1984). Measuring Labor Efficiency in Post Offices, In M. Marchand, P.Pestieau, H. Tulkens (eds.), The Performance of Public Enterprises: Concepts and Measurement, Amsterdam: NorthHolland, pp.243-267
6) Farrell, M.J. (1957): The measurement of productive efficiency, Journal of the Royal Statistical Society: Series A, Vol. 120, No. 3, pp. 253-290

7) Farrell, M.J., Fieldhouse, M. (1962): Estimating efficient production functions under increasing returns to scale, Journal of the Royal Statistical Society: Series A, Vol. 125, No. 2, pp. 252-267

8) Mihailović, B., Simonović, Z., Paraušić, V. (2009): Entropija kao mera organizacione neefikasnosti [In English: The entropy as a measure of organizational inefficiency], Industrija, Vol. 37, No. 3, pp. 109-121

9) Pejčić Tarle, S., Bojković N. (2012). Evropska politika održivog razvoja transporta [In English: The European policy on a sustainable transport development], Belgrade: Faculty of Transport and Traffic Engineering.

10) Porcelli, F. (2009). Measurement of Technical Efficiency. A brief survey on parametric and non-parametric techniques. Available at: http://www.researchgate.net/publictopics.PublicPostFile Loader.html?id=55b724115dbbbd5 97e8b459c\&key=37c09bab-2729-4efd-bd7282d1b80d356b, Accessed Avg 20, 2015.

11) Ralević, P., Dobrodolac, M., Marković D. (2014): Using a nonparametric technique to measure the cost efficiency of postal delivery branches, Central European Journal of Operations Research, DOI: 10.1007/s10100014-0369-0

12) Ralević, P., Dobrodolac, M., Marković D., Finger, M. (2014): Stability of the Classifications of Returns to Scale in Data Envelopment Analysis: A Case Study of the Set of Public Postal Operators, Acta Polytechnica Hungarica, Vol. 11, No. 8, pp. 177-196

13) Ralević, P., Dobrodolac, M., Marković, D., Mladenović, S. (2015): The Measurement of Public Postal Operators' Profit Efficiency by Using Data Envelopment Analysis (DEA): a Case Study of the European Union Member States and Serbia, Engineering Economics, Vol. 26, No. 2, pp. 159-168

14) Republic of Serbia (2005). Zakon o poštanskim uslugama [In English: The Law on Postal Services], Belgrade: National Assembly of the Republic of Serbia.

Paper sent to revision: 23.06.2015.

Paper ready for publication: 29.08.2015. 